\title{
BMJ Open Sick leave and return to work after surgery for type II SLAP lesions of the shoulder: a secondary analysis of a randomised sham-controlled study
}

\author{
Jens Ivar Brox (D) , ${ }^{1,2}$ Øystein Skare, ${ }^{3}$ Petter Mowinckel, ${ }^{4}$ Jostein Skranes Brox, ${ }^{5}$ \\ Olav Reikerås, ${ }^{6}$ Cecilie Piene Schrøder ${ }^{3}$
}

To cite: Brox Jl, Skare $\emptyset$, Mowinckel P, et al. Sick leave and return to work after surgery for type II SLAP lesions of the shoulder: a secondary analysis of a randomised shamcontrolled study. BMJ Open 2020;10:e035259. doi:10.1136/ bmjopen-2019-035259

- Prepublication history for this paper is available online. To view these files, please visit the journal online (http://dx.doi org/10.1136/bmjopen-2019035259).

Received 24 0ctober 2019 Revised 05 February 2020 Accepted 02 March 2020

\section{Check for updates}

(c) Author(s) (or their employer(s)) 2020. Re-use permitted under CC BY-NC. No commercial re-use. See rights and permissions. Published by BMJ.

${ }^{1}$ Department of Physical Medicine and Rehabilitation, Oslo University Hospital, Oslo, Norway

${ }^{2}$ Institute of Clinical Medicine, Faculty of Medicine, University of Oslo, Oslo, Norway

${ }^{3}$ Surgical Department, Lovisenberg Deakonal Hospital, Oslo, Norway

${ }^{4}$ Oslo University Hospital, Oslo, Norway

${ }^{5}$ Copenhagen Business School, Frederiksberg, Denmark

${ }^{6}$ Orthopedic Department, Oslo University Hospital, Oslo, Norway

Correspondence to

Dr Jens Ivar Brox;

j.i.brox@medisin.uio.no

\section{ABSTRACT}

Objectives To compare days on sick leave and assess predictors of return to work following shoulder surgery. Design A secondary analysis of a randomised controlled trial.

Setting Orthopaedic department.

Participants 114 patients with type II superior labral tear from anterior to posterior of the shoulder.

Interventions Labral repair, biceps tenodesis or sham surgery.

Outcome measures Sick leave was obtained from national registers for the last year before and 2 years following surgery. Total and shoulder related number of days on sick leave were obtained, using international diagnostic codes. We applied the difference-in-difference approach to compare the differences in the change in mean work days on sick leave between groups over time, backwards logistic regression and lasso regression to evaluate predictors.

Results Mean total number of work days on sick leave during the 2 years after surgery was 148 (range $0-460$ ) days. More than $80 \%$ of the sick leave days were taken by $22 \%$ of the patients. Days on sick leave classified as shoulder-related constituted $80 \%$ of the total. In all three treatment groups, the mean total number of days on sick leave doubled the year after surgery. Sham surgery and labral repair had fewer postoperative sickness absence days compared with biceps tenodesis but differences were not significant when adjusted for days of sick leave the year before surgery. Predictors of return to work at 2 years analysed by logistic regression were no sick leave (OR 8.0, $95 \% \mathrm{Cl} 2.4$ to 26.0 ) and moderate symptoms of anxiety or depression ( $0 \mathrm{R} 0.16,95 \% \mathrm{Cl} 0.05$ to 0.5 ) at inclusion. Similar results were obtained by lasso regression but manual work was an additional predictor.

Conclusions Change in mean work days on sick leave comparing sham surgery, labral repair and biceps tenodesis, was not significantly different. Sick leave, symptoms of anxiety and depression, and manual work at inclusion predicted work status 2 years after surgery. Trial registration number NCT00586742.

\section{INTRODUCTION}

Up to one half of the population has experienced shoulder pain in the last year and
Strengths and limitations of this study

- Strengths of the study include a randomised design, sham surgery control group, validated outcome measures, no drop-outs, and blinded follow-up and analyses.

- Sickness absence in clinical trials is often based on self-report. In the present study, data on sick leave was derived from a complete national register, coded by a blinded independent coworker.

- Limitations include the small sample size, lack of a detailed evaluation of work demands and lack of a non-surgical control group.

shoulder pain is regarded as the third most common musculoskeletal problem. ${ }^{1-3}$ In a recent Norwegian study, upper-limb problems including shoulder pain, were the most frequent musculoskeletal pain localisation among employed people in primary care, and about one-fourth were on sick leave. ${ }^{4}$ Some of these patients are expected to be referred for shoulder surgery, and operative treatments receive public reimbursement in Norway in order to get patients back to work faster. There is little evidence of the cost-benefit and effectiveness of interventions on sickness absence and return to work in patients with musculoskeletal pain. ${ }^{5}$ Epidemiological studies indicate that the use of arthroscopic shoulder surgery has risen dramatically over the last decades despite trials dating back to 1993 failing to demonstrate any clear benefit compared with physiotherapy. ${ }^{6-13}$ Twenty-one thousand shoulder arthroscopic procedures were performed in public (National Health Service) hospitals in England in 2010, at an estimated cost of $£ 50$ million. ${ }^{6}$

Two recently published sham-controlled trials on arthroscopic acromion resection for subacromial pain and one trial on biceps tenodesis or labral repair for a glenoid labral 
disorder, superior labrum tear from anterior to posterior (type II superior labral tear from anterior to posterior (SLAP) lesion), have failed to demonstrate any benefit of these surgical procedures over sham surgery on selfreported pain and disability. ${ }^{14-16}$ Results for sickness absence have not yet been reported. From a societal perspective, costs of sick leave accounted for $84 \%$ of the total costs for shoulder pain in primary care. ${ }^{17}$ Sickness absence and productivity loss are indirect costs that in addition to direct medical costs such as consultation fee, medication, physiotherapy and surgery, make up the total costs.

Because the published sham-controlled studies found no improvement in self-reported pain or disability as a result of surgery, difference in sickness absence may not be expected. Nevertheless, reporting results on sickness absence is considered to be important both from a patient perspective and a societal perspective. Besides, previously published results include pain and disability, which are subjective self-report outcomes, while sickness absence may be objectively obtained from official registers and yield different findings.

Sickness absence and unemployment are not just regarded as important socioeconomic problems, they also represent additional public risk factors predicting future health-related quality of life and morbidity. ${ }^{1819}$ The causes of sickness absence are considered to be multifactorial. Musculoskeletal and mental symptoms, as well as workrelated and sociodemographic factors are considered to be the most important factors contributing to sickness absence. ${ }^{20}{ }^{21}$ There is little knowledge about predictors of return to work after shoulder surgery. Age, previous sick leave, education, job demands, mental symptoms, multimorbidity and effectiveness of surgery on pain and disability, are factors possibly associated with return to work. $^{422-29}$

From the surgeons' perspective, pathoanatomical changes observed by imaging or by the arthroscope are emphasised as determinants of sick leave and return to work. Indication for surgery is based on the repair model, which proposes that repair or resection will reduce pain and disability and enable the patient to return to work. Problems in applying this approach are that findings from imaging are often asymptomatic, ${ }^{30}$ treatment may be ineffective and other factors are important for returning to work. The challenge of diagnosing the patient's problem and recommending the best treatment is apparently the case with labral lesions of the shoulder because a recent study reported a high prevalence $(55 \%-72 \%)$ of labral lesions on MRI among asymptomatic middle-aged (45-60 years) people. ${ }^{31}$ There is little evidence on return to work after surgery for labral lesions in particular, but one retrospective small study reported that patients on workers' compensation had poorer clinical results. ${ }^{32}$ In another small study including patients on workers' compensation, only $44 \%$ had returned to work at their previous level at an average follow-up of 2.5 years. ${ }^{33}$

From 2008 to 2016, we conducted a randomised trial to compare the efficacy of labral repair, biceps tenodesis and sham surgery. ${ }^{15} 34$ All patients had standardised postoperative physiotherapy. We found no group differences in improvements in pain and disability, as measured by the primary outcomes of Rowe score and Western Ontario Shoulder Instability Index (WOSI) at 6 months, and at 1 and 2 years. ${ }^{15}$ The aim of the present study is to compare the differences in the change in mean work days on sick leave between groups over time, and to evaluate predictors of return to work at 2-year follow-up. ${ }^{15}$

Table 1 Baseline characteristics of patients

\begin{tabular}{lccc}
\hline Outcome & $\begin{array}{l}\text { Biceps tenodesis } \\
(\mathbf{n}=\mathbf{3 8})\end{array}$ & $\begin{array}{l}\text { Sham surgery } \\
(\mathbf{n}=\mathbf{3 6})\end{array}$ & $\begin{array}{l}\text { Labral repair } \\
(\mathbf{n}=\mathbf{4 0})\end{array}$ \\
\hline Age (years), mean (SD) & $37.0(7.7)$ & $41.2(9.7)$ & $40.5(9.1)$ \\
Age $<$ 40 years, $\mathrm{n}(\%)$ & $22(57.9)$ & $14(38.8)$ & $17(42.5)$ \\
\hline Females, $\mathrm{n}(\%)$ & $15(38.5)$ & $14(38.8)$ & $17(42.5)$ \\
\hline Body mass index, mean (SD) & $27.7(5.6)$ & $26.4(3.8)$ & $26.4(4.3)$ \\
University education, $\mathrm{n}(\%)$ & $18(47.3)$ & $20(55.6)$ & $22(56.4)$ \\
Manual work, $\mathrm{n}(\%)$ & $18(47.3)$ & $11(30.6)$ & $17(42.5)$ \\
$\quad$ Taking analgesics daily or weekly, $\mathrm{n}(\%)$ & $7(18.4)$ & $5(13.9)$ & $6(15.0)$ \\
Duration of shoulder symptoms $>1$ year, $\mathrm{n}(\%)$ & $29(76.3)$ & $29(80.6)$ & $25(62.5)$ \\
$\quad$ Dominant shoulder involved, $\mathrm{n}(\%)$ & $27(71.2)$ & $30(83.3)$ & $28(70.0)$ \\
WOSI (0-21 00), mean (SD) & $1145(392)$ & $1025(381)$ & $1044(316)$ \\
Rowe (0-100), mean (SD) & $60.3(10.0)$ & $63.6(10.9)$ & $62.7(9.7)$ \\
$\quad$ Reporting symptoms of anxiety or depression, $\mathrm{n}(\%)$ & $10(26.3)$ & $9(25.0)$ & $12(30.0)$ \\
On sick leave, $\mathrm{n}(\%)$ & $18(47.4)$ & $12(33.3)$ & $15(37.5)$ \\
\hline
\end{tabular}

WOSI, Western Ontario Shoulder Instability Index. 


\section{METHODS}

\section{Participants and setting}

From 2008 to 2014, we recruited 118 patients with clinical symptoms and signs, positive MRI arthrography and arthroscopically verified isolated type II SLAP lesion. All patients had at least one positive clinical sign of a SLAP lesion and failed previous non-operative treatment. ${ }^{15435}$ The median age of the patients was 40 (range 18-64) years, and $47(40 \%)$ were women. In the present study on sickness absence, we included all patients registered at the National Insurance Company. Four patients who were not employed at baseline were excluded (three students and one on disability pension). Baseline characteristics of the 114 patients analysed in the present study are reported in table 1 .

All patients were operated by the same surgeon at the surgical department of Lovisenberg Deaconal Hospital in Oslo, which performs the largest number of operations for type II SLAP lesions in Norway. The hospital primarily serves patients from the Oslo area, but also serves patients whole South-Eastern Region of Norway with a population of about 2.6 million.

\section{Randomisation and intervention}

Patients with a suspected isolated type II SLAP lesion on clinical examination and MRI arthrography had arthroscopic diagnostic examination. Following confirmation of an isolated type II SLAP lesion, the patient was included in the randomisation procedure. An independent statistician used the permuted block method of randomisation. Concealed allocation was organised by an independent secretary who distributed sealed opaque numbered envelopes to the head nurse in the operating room. The nurse opened the envelope and informed the surgeon about the allocated procedure to be performed.

Patients were randomly allocated to either labral repair, biceps tenodesis or sham surgery (figure 1). All patients had a standardised postoperative physiotherapy regimen provided by a physiotherapist or a manual therapist in primary healthcare. The full protocol and clinical results, including a detailed description of recruitment, inclusion, randomisation, treatment, follow-up of patients, have been described previously. ${ }^{15} 34$ There were no major harms.

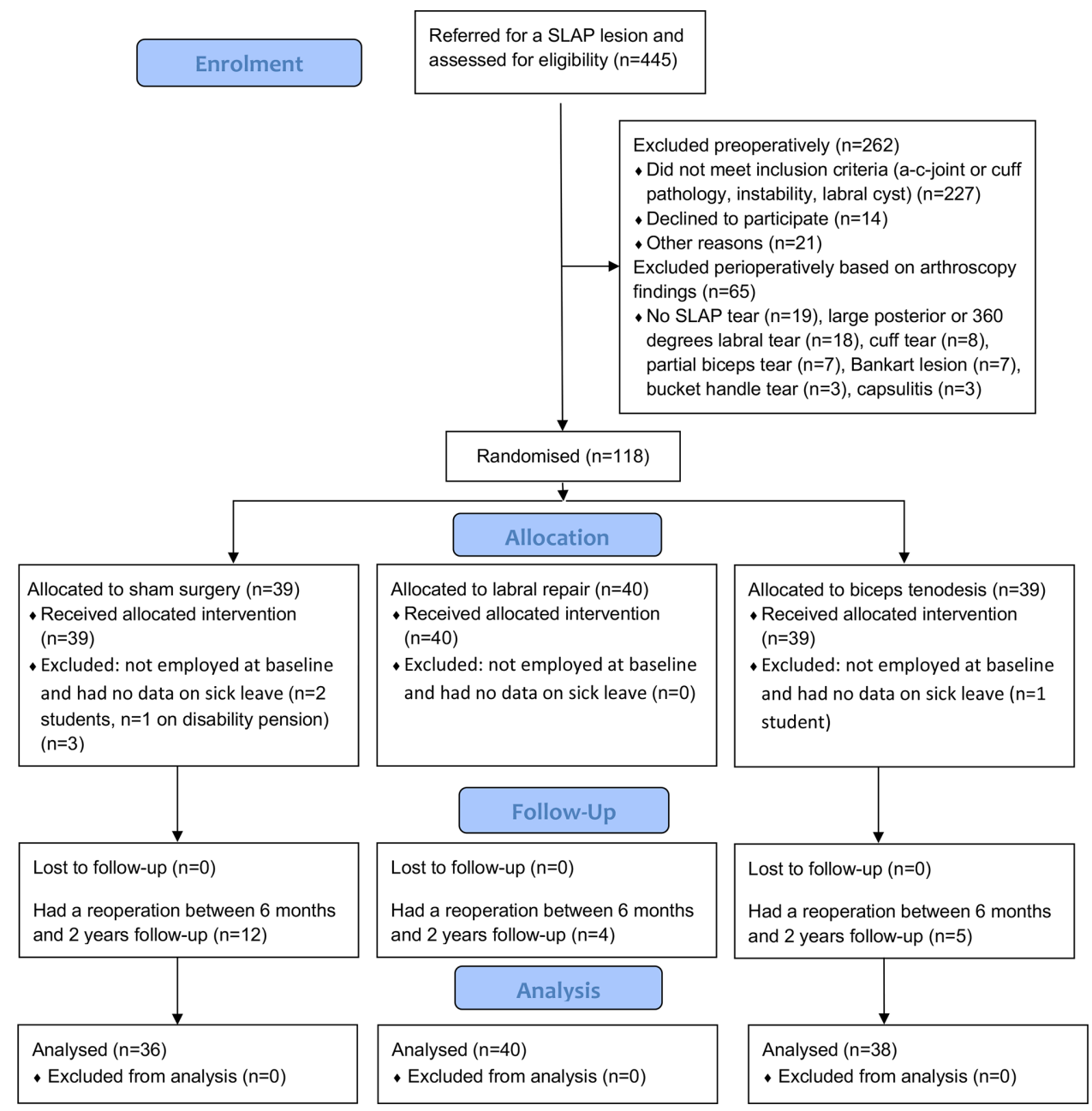

Figure 1 Consolidated Standards of Reporting Trials flow diagram. SLAP, superior labral tear from anterior to posterior. 


\section{Measurements}

\section{Sick leave}

The outcomes in the present study are days on sick leave and return to work. We did not use self-reported days on sick leave because it has previously been reported to be unreliable. $^{36}$ Data were obtained from the Norwegian Labour and Welfare Administration. All lawful residents of Norway are included in the Norwegian public insurance system, which provides health services, social service benefits and pensions for all members of the National Insurance Scheme. The workers' compensation programme provides $100 \%$ coverage for lost income due to medically acknowledged sickness, disease or injury from the first day until the person can work again. The programme covers up to 52 weeks, and thereafter long-term benefits provide approximately $66 \%$ of former income. Patients can have long-term benefits for years until they receive disability pension, social security service or return to work. Only sick leave prescribed by a health care provider (physician, manual therapist or chiropractor) was recorded.

In Norway, workers are additionally allowed to prescribe themselves 10 days of sick leave per year without consulting a healthcare provider. This self-prescribed sickness absence was not recorded. Days with benefits registered as sickness absence (including sick leave for the first 52 weeks and thereafter long-term benefit) were summarised. Graded sick leave was registered in percentage of a full working day. For example, $50 \%$ sickness benefit for 5 days was converted to 2.5 days of sick leave. We estimated approximately 230 working days per year in Norway, and applied the maximal number of days on sickness absence of 230 days per year. In the present study, most patients in all three treatment groups routinely took about 6 weeks (30 working days) of sick leave after surgery.

Any sick leave, regardless of the diagnostic code applied, was registered. If any of the following diagnostic codes were used, sick leave was classified as shoulderrelated: ICD-10 (International Classification of Diseases and Related Health Problems, 10th Edition) M75, S40S49 or T03.2; ICPC L08, L80, L81, L87, L91, L92, L98 or L99. Five patients did not have data on sick leave in the national register. One was on disability pension (sham), three were students (two had sham and one biceps tenodesis) and one was never on sick leave (labral repair). The first four were not employed at baseline and were excluded from the study, but the one who was employed and did not take sick leave was included. We specified neither the method for calculating the number of days on sick leave nor the possible predictors for return to work in the published study protocol, ${ }^{34}$ but the analysis strategy was planned before sick leave data were registered.

\section{Predictors and clinical data}

The trial's primary clinical outcomes were the Rowe score and the WOSI at 6 and 24 months after surgery. We previously reported no differences in clinical outcomes or harms for the three treatment groups, and there were no major harms in any of the three groups. ${ }^{15}$ Patient report questionnaires were used to register predictors at baseline. Older age and low education were associated with sick leave in a recent Norwegian epidemiological study ${ }^{4}$ and both were registered as possible predictors of return to work at 2 years. Education was dichotomised as high (university education) or low (any other education). Occupations involving a high intensity of force and upper arm elevation $>90^{\circ}$ were associated with increased rates of surgery for subacromial pain in a recent Danish study. ${ }^{22}$ We were not able to obtain an expert evaluation of work load in the included patients. Work was classified as manual if the patient reported to be engaged in daily manual work at the work place. Symptoms of anxiety and depression are possible predictors of disability and sickness absence. For example, depression scores predicted disability in a recent large Norwegian study among patients accepted for rehabilitation. ${ }^{23} \mathrm{~A}$ single question about depression has been shown to be a valid screening tool. ${ }^{37}$ We obtained baseline information on symptoms of anxiety and depression from the EQ-5D and dichotomised answers into no symptoms or moderate/severe symptoms of anxiety and depression. ${ }^{38}$

\section{Blinding}

The patients, the treating physiotherapists/manual therapists and the persons collecting and analysing the data, including sick leave, were blinded to group assignment.

\section{Statistical analysis}

The sample size in the randomised study was calculated to detect a clinically important difference of 10 points in the mean Rowe score. Sickness absence and return to work were listed as secondary outcomes in the published protocol but the statistical approach for these outcomes were not specified and analyses are therefore considered as post-hoc.

Results are presented as means (SD or $95 \%$ CI), medians (range), numbers (percentages) or OR (95\% CI). We conducted separate analyses for shoulder-related sick leave according to the ICD-10 diagnoses described earlier. Because data were skewed, we used non-parametric methods to compare the number of work days on sick leave the year before surgery, and from 0 to 6 months, 0 to 12 months and 12 to 24 months after surgery. We used that we had exact data on sick leave the year before the interventions and for 2 years after the interventions. The difference-in-difference (DID) approach was used to compare the differences in the change in mean work days on sick leave between groups over time. This statistical method originated in the field of econometrics and is also called 'controlled before-and-after study'. DID is commonly used in studies where randomisation is not possible. ${ }^{39}$ In the present study we used DID because we observed a significant difference in workdays on sick leave between groups before surgery, because data were skewed and because we had not obtained data on factors that may have influenced sick leave such as income, working 
conditions and prescription practice of physicians. We attempted to obtain an unbiased estimate of the effect of the different treatments on sick leave by comparing the changes in outcome over time. We assumed that the effect of the unobserved factors was constant over time. In particular, we assumed that the patients did not change physicians prescribing sickness absence certificates and that patients' working conditions and income stayed the same. DID was implemented as an interaction term between time and treatment group in a regression model. Results were analysed according to the principle of intention to treat.

In addition, we calculated the percentage of patients who had $>200$ days on sick leave during the 2 years of follow-up after surgery; compared the number of days on sick leave in those who had a reoperation with those who did not have a reoperation; and compared the clinical outcomes (Rowe and WOSI) at 2-year follow-up between those who had returned to work and those who had not.

Predictors of return to work at 2 years were evaluated by logistic backwards stepwise regression entering variables associated with return to work in the univariate analyses $(\mathrm{p}<0.20)$. In planning the analysis we hypothesised that the following variables could be associated with return to work 2 years after surgery: work days on sick leave the year before surgery; self-reported manual work (yes/ no); university education (yes/no); age; sex; duration of shoulder symptoms; >1 year (yes/no) treatment group; dominant shoulder involved (yes/no); anxiety/depression (none/moderate); baseline Rowe score.

Lasso penalised logistic regression was also conducted for model selection using the glmnet package in $\mathrm{R}^{40}{ }^{41}$ The lasso model estimates the coefficients by minimising some objective function (in our case the negative loglikelihood function) under the constraint that the sum of the absolute values of the coefficients is less than or equal to some $\lambda$. This constraint, or penalty term, forces some of the coefficients to be equal to zero when $\lambda$ gets sufficiently large, thereby resulting in a sparse model that only contains a subset of the variables. To obtain $\lambda$ we performed fivefold-cross-validation. Since the folds are selected at random, and our sample size is quite small, the results was subject to some noise. To account for this randomness, we replicated the process above 500 times and averaged the deviance across all values of $\lambda$. We then choose the $\lambda$ with the lowest mean deviance across all samples.

\section{Ethics and registration}

All patients provided written informed consent. The protocol was registered at ClinicalTrials.gov. The study is reported according to the Consolidated Standards of Reporting Trials guidelines.

\section{Patient and public involvement}

Patients and the public were not directly involved in planning this study.
RESULTS

\section{Sick leave}

The design and conduction of the trial is reported in the flow chart (figure 1). Only patients employed at baseline and registered by the National Insurance Company were analysed (114 of 118 patients). Baseline characteristics for the 114 patients are described in table 1 . The mean total number of working days on sick leave during the 2 years following surgery was 148 (range 0-460) for the whole study cohort. In the follow-up period, $80.7 \%$ of the sickness benefit days were taken by $21.9 \%$ of the patients. All interventions had patients with $>200$ days on working days on sick leave while one patient returned to work the day after surgery. The mean number of working days on sick leave after surgery was 65 (95\% CI 46 to 85 ) days among patients $(n=44)$ with $<10$ days of sick leave the year before surgery and 92 (95\% CI 47 to 136) days in patients with 10-50 days.

Sick leave in the year after surgery more than doubled in all groups compared with the year before surgery (table 2). Working days on sickness benefit for diagnoses classified as shoulder-related constituted $80 \%$ of the total. Two patients were not included in results on shoulderrelated sickness absence because we were not able to determine the diagnosis for sick leave.

The median number of working days on sick leave (total and shoulder-related) the year before (baseline) and until 1 year after surgery were higher in the biceps tenodesis group (table 2).

Comparison of differences in working days on sick leave between 0 and 6 months, 0 and 12 months and 12 and 24 months postsurgery adjusted for the difference before surgery are presented in table 3 . We found no significant differences between groups in the change in the mean total or shoulder related working days on sick leave for any of time periods.

\section{Clinical outcome and reoperation}

The primary outcomes were similar in patients who had or had not returned to work at 2 years (Rowe 86.4 (SD 14.0), WOSI 404 (SD 401)) versus (Rowe 87.0 (SD 16.2), WOSI 413 (SD 399)). Twenty-one (18\%) had a reoperation (figure 1). Nine of these patients had not returned to work after 2 years. They had longer $(\mathrm{p}=0.001)$ sick leave (mean 229 (95\% CI 154 to 303) days) compared with those not reoperated (mean 130 (95\% CI 107 to 152) days).

\section{Predictors of return to work}

Overall, 89 patients (78\%) had returned to work at 2-year follow-up, including $62(90 \%)$ of the 69 patients who were not on sick leave at inclusion, and $27(60 \%)$ of the 45 patients on sick leave at inclusion $(\mathrm{p}<0.001)$. Seventeen $(55 \%)$ of the 31 patients reporting symptoms (all had moderate symptoms) of anxiety and depression at baseline had not returned to work at 2 years versus only $11(87 \%)$ of 83 patients who did not report symptoms anxiety or depression $(\mathrm{p}<0.001)$. 
Table 2 Median (range) and mean (SD) number of working days on sick leave (total and shoulder-related) in the year prior to surgery and 0-6 months, 0-1 year and 0-2 years postsurgery*

\begin{tabular}{|c|c|c|c|c|}
\hline Sick leave & $\begin{array}{l}\text { Biceps tenodesis } \\
(n=38)\end{array}$ & $\begin{array}{l}\text { Sham surgery } \\
(n=36)\end{array}$ & $\begin{array}{l}\text { Labral repair } \\
(n=40)\end{array}$ & $P$ value \\
\hline \multicolumn{5}{|l|}{ 1-year presurgery } \\
\hline Total sick leave & $42(0-230) 60.2(56.4)$ & $11(0-230) 52.6$ (73.5) & $14(0-230) 52.9(70.9)$ & 0.22 \\
\hline Shoulder-related sick leave & $32(0-230) 53.1(57.0)$ & $0(0-230) 36.3(60.1)$ & $0(0-230) 37.2(64.3)$ & $0.043 \dagger$ \\
\hline \multicolumn{5}{|l|}{ 0-6 months postsurgery } \\
\hline Total sick leave & $97(10-115) 87.1$ (32.6) & $64(10-115) 66.1(35.7)$ & $65(0-115) 67.5$ (32.2) & $0.009 \ddagger$ \\
\hline Shoulder-related sick leave & $94(10-115) 84.9(33.4)$ & $52(10-115) 60.7$ (35.9) & $61(0-115) 61.9(32.7)$ & $0.003 \S$ \\
\hline \multicolumn{5}{|l|}{$0-1$-year postsurgery } \\
\hline Total sick leave & $113(15-230) 122.3(68.3)$ & 85 (23-230) 99.1 (59.8) & 75 (0-230) 90.4 (64.2) & 0.07 \\
\hline Shoulder-related sick leave & $108(10-230) 118.1(69.9)$ & $68(10-230) 84.3(54.3)$ & $61(0-230) 77.9(60.0)$ & 0.0169 \\
\hline \multicolumn{5}{|l|}{$1-2$ years postsurgery } \\
\hline Total sick leave* & $12(0-230) 46.1$ (69.5) & 8 (0-230) 53.3 (87.9) & $3(0-230) 34.4$ (70.2) & 0.25 \\
\hline Shoulder-related sick leave & 0 (0-230) $35.3(70.1)$ & 0 (10-230) 31.2 (72.1) & 0 (0-230) 19.9 (54.5) & 0.60 \\
\hline
\end{tabular}

${ }^{\star}$ Non-parametric statistics were used to compare differences between groups.

†Pairwise differences between groups were not significant $(p>0.05)$.

$\ddagger$ †iceps tenodesis had significantly more sick leave days than sham surgery $(p=0.034)$ and labral repair $(p=0.017)$.

$\S$ Biceps tenodesis had significantly more sick leave days than sham surgery $(p=0.012)$ and labral repair $(p=0.007)$.

|Biceps tenodesis had significantly more sick leave days than labral repair $(p=0.017)$.

No sick leave at inclusion was strongly associated with return to work 2 years after surgery while symptoms of anxiety or depression were inversely associated (table 4). The final model was similar to the model selected by backwards elimination, but with shrunken coefficient estimates due to the penalty term. Treatment group was not associated with return to work.

We entered sick leave at baseline, symptoms of anxiety and depression, manual work, age, sex, duration of shoulder pain education, dominant shoulder involved and baseline Rowe score in a stepwise backwards regression analysis. All variables except sick leave, anxiety and depression and manual work $(\mathrm{p}=0.15)$ were eliminated at the first step. Treatment entered to the final model. Analysis without treatment showed similar results McFadden $\mathrm{R}^{2}$ (0.23) and OR for sick leave (8.0 (95\% CI 2.4 to 26.0)) and anxiety and depression (0.17 (95\% CI 0.06 to 0.5$)$ ). Manual work was eliminated in the final logistic regression model but remained in the final lasso regression model.

\section{DISCUSSION}

Patients who had biceps tenodesis for type II SLAP lesion of the shoulder, had more postoperative work days on sick leave compared with sham surgery or labral repair but when adjusted for preoperative sick leave the change in mean work days on sick leave was not significantly different between treatments. The number of working days on sickness benefit increased following shoulder surgery compared with the year before surgery. Patients not on sick leave, not reporting symptoms of anxiety or

Table 3 Comparison in working days on sick leave between group differences from 1-year presurgery to 0-6 months, 0-12 months and $12-24$ months postsurgery. Mean $(95 \% \mathrm{Cl})$ differences between groups for total and shoulder related sick leave are given

\begin{tabular}{llll}
\hline Outcome & $\begin{array}{l}\text { Biceps tenodesis } \\
\text { vs labral repair }\end{array}$ & $\begin{array}{l}\text { Biceps tenodesis } \\
\text { vs sham surgery }\end{array}$ & $\begin{array}{l}\text { Labral repair } \\
\text { vs sham surgery }\end{array}$ \\
\hline 0-6 months total & $12.1(-21.3$ to 45.5$)$ & $13.2(-21.1$ to 47.5$)$ & $1.1(-32.8$ to 35.0$)$ \\
\hline $0-6$ months shoulder & $7.1(-23.9$ to 38.2$)$ & $7.5(-24.4$ to 39.4$)$ & $0.4(-31.3$ to 32.1$)$ \\
$0-12$ months total & $24.6(-16.8$ to 25.9$)$ & $15.5(-26.9$ to 57.9$)$ & $-9.1(-51.0$ to 32.8$)$ \\
$0-12$ months shoulder & $24.3(-14.4$ to 63.0$)$ & $17.0(-22.8$ to 56.7$)$ & $-7.3(-46.9$ to 32.2$)$ \\
12-24 moths total & $4.4(-40.7$ to -49.4$)$ & $-14.9(-61.1$ to 31.4$)$ & $-19.2(-64.9$ to \\
12-24 months shoulder & $-0.5(-40.4$ to 39.5$)$ & $-12.8(-53.9$ to 28.3$)$ & $26.5)$ \\
& & & $-12.3(-53.2$ to \\
\hline
\end{tabular}


Table 4 Final models of baseline predictors of return to work at 2 years postsurgery

\begin{tabular}{llll}
\hline & $\begin{array}{l}\text { Logistic } \\
\text { regression } \\
\text { OR (95\% }\end{array}$ & & \\
& Cl) & P value & $\begin{array}{l}\text { Lasso } \\
\text { regression }\end{array}$ \\
\hline Sick leave* (no vs yes) & $\begin{array}{l}8.0(2.4 \text { to } \\
26.0)\end{array}$ & $<0.001$ & 3.38 \\
\hline $\begin{array}{l}\text { Anxiety/depression† } \\
\text { (moderate vs none) }\end{array}$ & $\begin{array}{l}0.16(0.05 \\
\text { to } 0.5)\end{array}$ & $<0.001$ & 0.36 \\
Manual work (yes vs no) & & \\
\hline $\begin{array}{l}\text { Treatment } \\
\text { Labral repair versus } \\
\text { sham }\end{array}$ & $\begin{array}{l}0.9(0.2 \text { to } \\
3.2)\end{array}$ & 0.82 & \\
\hline $\begin{array}{l}\text { Biceps tenodesis versus } \\
\text { sham }\end{array}$ & $\begin{array}{l}1.6(0.4 \text { to } \\
6.7)\end{array}$ & 0.51 & \\
\hline
\end{tabular}

McFadden $\mathrm{R}^{2}=0.24$, AIC (Akaike Information Criterion)

$=93.18, n=109$.

*Data from the National Insurance Company.

†Self-reported symptoms, not recognised by the treating physician.

depression or not on manual work at inclusion had higher odds of returning to work within 2 years after surgery.

\section{Strengths and weaknesses of the study}

The main strengths are the randomised design, inclusion of sham surgery, blinded follow-up and analyses, high follow-up rate, the use of validated outcomes and data on sick leave derived from a complete national register, coded by a blinded independent coworker. We obtained the diagnosis registered for sickness certification in all but two patients. The total number of working days on sick leave was only slightly higher than shoulder-related sick leave. The difference observed in working days on sick leave at inclusion in the present study was not expected. Similar baseline scores on the trial's primary outcomes suggest that the randomisation succeeded and that the difference between groups in sick leave the year before surgery is due to chance. ${ }^{15}$ The adjustment for working days on sick leave the year before surgery is therefore considered a strength of the present study.

A limitation of the present trial is the lack of a nonsurgical group. In planning the study, the primary aim was to evaluate the efficacy of two surgical procedures and we expected that it would be difficult to include a non-treatment group or one that was only provided physiotherapy. An inclusion of either group would have provided valuable information on sick leave in a nonoperative group. Other factors indicate that surgery should not be recommended to reduce sickness absence: on average, the repairs provided no benefit over the sham intervention, mean duration of sick leave postsurgery was very long and sick leave at inclusion and anxiety and depression were the only predictors of patients' return to work at 2-year follow-up.
A detailed evaluation of the type of work performed, income and variation among physicians and indications for prescriptions of sickness absence certificates, was beyond the scope of this study.

Another limitation is the number of cross-overs (figure 1). We found no difference in the clinical outcome before reoperation in the cross-overs from the sham group compared with a similar number of patients with poor clinical results in the two other intervention groups. ${ }^{15}$ Our interpretation was that the difference in the number of cross-overs between groups was mainly due to the design of the study. Both the patients and the surgeon believed that repair was indicated if improvement was slow, while for those who already had a repair the threshold for reoperation was higher. A reoperation increased number of work days on sick leave. Finally, the strict inclusion criteria based on history including previous treatment; clinical examination; preoperative MRI arthrography and peroperative arthroscopic diagnostic evaluation, are likely to improve the internal validity of the study, but together with the limited sample size, also reduce generalisability of the trial findings.

\section{Results in relation to other studies}

While we found no difference between treatments, a recent review concluded that biceps tenodesis was costeffective compared with labral repair or non-operative treatment. ${ }^{42}$ The review was mainly based on data from cohort studies. In their analyses, probability values were partly based on assumptions of unpublished estimated costs for absence from work at 6 months derived from our study. Their conclusion may be misleading as we previously reported no benefit from biceps tenodesis compared with labral repair in terms of quality of life benefit and in the present secondary analysis report no benefit in indirect costs such as work days on sick leave.

Because of different welfare systems, sickness absence and treatment costs are difficult to compare between countries. By example, in Norway all employed citizens have a full economic compensation the first year on sick leave. Most surgery is public and patients pay only about $€ 30$ for labral surgery. Sick leave was estimated to 13 days in the review, about $10 \%$ of what we have reported. Considering different welfare systems, 13 days is still very low because some patients in most countries perform manual work and need longer time off work, and some are on sick leave and have symptoms of anxiety and depression before surgery. Norway, Denmark and Sweden had the highest public spending (about $4 \%$ of goss domestic product) on incapacity for work due to sickness, disability and occupational injury. ${ }^{43}$ Norway had the highest number of days (14.6 days in 2018) per person per year of compensated absence. ${ }^{44}$ The OECD (Organisation for Economic Co-operation and Development) statistics demonstrates the association between perceived health status and estimates of social inequality such as income and length of education. 
Similar to the findings in the present study, a study in primary care reported that about one-fifth of the patients accounted for more than four-fifths of the number of days on sick leave. ${ }^{17}$ The costs for sick leave contributed to $84 \%$ of the total costs. One day on sick leave in Norway was estimated to $€ 289$ in 2012. ${ }^{45}$ Based on daily costs for 1 day on sick leave, an average of 148 work days of sick leave in the present study, and roughly estimated costs of surgery at $€ 5000$ in Norway, the relative contribution of sickness benefit to total costs in secondary care is considered to be about similar to primary care. This underlines the importance of considering high indirect costs of sickness absence in addition to the direct surgical costs. The long spells of sickness absence indicate that high societal costs are expected for arthroscopic labral surgery.

\section{Predictors of return to work}

Obstacles for return to work should preferably be identified at an early stage, and the patients should be referred for an evidence-based approach to help to solve their problem. A Cochrane review and a recent randomised trial concluded that work-directed psychological interventions reduce sickness absence compared with usual care for patients with depression. ${ }^{46} 47$ These results support policy shifts towards integrating work and health services for people with common mental disorders and providing long-term benefits. One-fourth of the patients included in the present study reported symptoms of anxiety and/ or depression at baseline. The occurrence of symptoms is comparable to middle aged patients with idiopathic scoliosis answering the same question. ${ }^{48}$ The number of patients with diagnosed anxiety or depression was much lower. Patients in the present study had to our knowledge no diagnosis of anxiety and depression at referral. A simple question can be used to help clinicians to identify these patients. ${ }^{37} 45$ It is therefore recommended that shoulder surgeons include a simple question in their preoperative assessment and refer patients at risk for anxiety or depression for a more comprehensive evaluation.

Consistent with our results, two small studies reported that a lower rate of patients on workers' compensation versus patients not on workers' compensation returned to work after labral surgery. ${ }^{32}{ }^{33}$ The average duration of sick leave was not reported. A systematic review on treatments of subacromial pain found that duration of sick leave was seldom included as an outcome measure. ${ }^{29}$ The results of the present study underline the importance of assessing sick leave as an objective outcome and predictor in studies including patients with chronic shoulder pain.

The indication for labral surgery and the choice of surgical method has been debated, particularly in patients over 40 years of age with common patho-anatomical MRI findings of the glenoid labrum. ${ }^{31}$ We found no influence of age on clinical outcome nor on sickness absence. In contrast, age has previously been reported to influence clinical outcome after labral repair and the number of days on sick leave after acromioplasty and rotator cuff repair. ${ }^{1025}{ }^{49}$ Similar to our study, mean days on sick leave after rotator cuff repair was 157 days. ${ }^{43}$

We conclude that in patients with type II SLAP lesion, biceps tenodesis and labral repair did not change mean work days on sick leave compared with sham surgery. Sick leave increased after surgery, independent of the treatment group. No symptoms of anxiety or depression, no sick leave and not on manual work at inclusion, predicted return to work 2 years after surgery.

Contributors CPS, OR and JIB conceived and designed the study. ØS and PM participated in setting up the study and writing the protocol. ØS and CPS recruited the patients and organised the study. CPS operated on all the patients. $\emptyset$ S provided blinded follow-up of all the patients. JSB (blinded to the treatment) entered the data, including collection and coding of National Insurance sick leave data for each patient. PM and JSB conducted the statistical analyses. JIB wrote the manuscript and all the authors gave critical comments and final approval of the submitted version.

Funding Lovisenberg Deakonal Hospital funded the study.

Competing interests None declared.

Patient and public involvement Patients and/or the public were not involved in the design, or conduct, or reporting, or dissemination plans of this research.

Patient consent for publication Not required.

Ethics approval This study was approved (IRB00001870) by the Ethics Commitee Health Region Southeast, Oslo, Norway. The study was conducted according to the Declaration of Helsinki.

Provenance and peer review Not commissioned; externally peer reviewed.

Data availability statement Data are available in a public, open access repository. Extra data can be accessed via the Dryad data repository at http://datadryad.org/ with the doi: $10.5061 /$ dryad.pzgmsbcgr.

Open access This is an open access article distributed in accordance with the Creative Commons Attribution Non Commercial (CC BY-NC 4.0) license, which permits others to distribute, remix, adapt, build upon this work non-commercially, and license their derivative works on different terms, provided the original work is properly cited, appropriate credit is given, any changes made indicated, and the use is non-commercial. See: http://creativecommons.org/licenses/by-nc/4.0/.

\section{ORCID iD}

Jens Ivar Brox http://orcid.org/0000-0002-2507-1812

\section{REFERENCES}

1 Luime JJ, Koes BW, Hendriksen IJM, et al. Prevalence and incidence of shoulder pain in the general population; a systematic review. Scand J Rheumatol 2004;33:73-81.

2 Natvig B, Nessiøy I, Bruusgaard D, et al. [Musculoskeletal complaints in a population. Occurrence and localization]. Tidsskr Nor Laegeforen 1994;114:323-7.

3 Bot SDM, van der Waal JM, Terwee CB, et al. Incidence and prevalence of complaints of the neck and upper extremity in general practice. Ann Rheum Dis 2005;64:118-23.

4 Gjesdal S, Holmaas TH, Monstad K, et al. New episodes of musculoskeletal conditions among employed people in Norway, sickness certification and return to work: a multiregister-based cohort study from primary care. BMJ Open 2018;8:e017543.

5 Palmer KT, Harris EC, Linaker C, et al. Effectiveness of communityand workplace-based interventions to manage musculoskeletalrelated sickness absence and job loss: a systematic review. Rheumatology 2012;51:230-42.

6 Judge A, Murphy RJ, Maxwell R, et al. Temporal trends and geographical variation in the use of subacromial decompression and rotator cuff repair of the shoulder in England. Bone Joint J 2014;96B:70-4.

7 Svendsen SW, Frost P, Jensen LD. Time trends in surgery for nontraumatic shoulder disorders and postoperative risk of permanent work disability: a nationwide cohort study. Scand J Rheumatol 2012;41:59-65. 
8 Weber SC, Martin DF, Seiler JG, et al. Superior labrum anterior and posterior lesions of the shoulder: incidence rates, complications, and outcomes as reported by American Board of orthopedic surgery. Part II candidates. Am J Sports Med 2012;40:1538-43.

9 Vitale MA, Arons RR, Hurwitz S, et al. The rising incidence of acromioplasty. J Bone Joint Surg Am 2010;92:1842-50.

10 Erickson BJ, Jain A, Abrams GD, et al. Slap lesions: trends in treatment. Arthroscopy 2016;32:976-81.

11 Brox JI, Staff PH, Ljunggren AE, et al. Arthroscopic surgery compared with supervised exercises in patients with rotator cuff disease (stage II impingement syndrome). BMJ 1993;307:899-903.

12 Haahr JP, Andersen JH. Exercises may be as efficient as subacromial decompression in patients with subacromial stage II impingement: 4-8-years' follow-up in a prospective, randomized study. Scand $J$ Rheumatol 2006;35:224-8.

13 Ketola S, Lehtinen J, Rousi T, et al. No evidence of long-term benefits of arthroscopicacromioplasty in the treatment of shoulder impingement syndrome: five-year results of a randomised controlled trial. Bone Joint Res 2013;2:132-9.

14 Beard DJ, Rees JL, Cook JA, et al. Arthroscopic subacromial decompression for subacromial shoulder pain (CSAW): a multicentre, pragmatic, parallel group, placebo-controlled, three-group, randomised surgical trial. Lancet 2018;391:329-338.

15 Schrøder CP, Skare Øystein, Reikerås $\mathrm{O}$, et al. Sham surgery versus labral repair or biceps tenodesis for type II slap lesions of the shoulder: a three-armed randomised clinical trial. Br J Sports Med 2017;51:1759-66.

16 Paavola M, Malmivaara A, Taimela S, et al. Subacromial decompression versus diagnostic arthroscopy for shoulder impingement: randomised, placebo surgery controlled clinical trial. BMJ 2018;362:k2860.

17 Virta L, Joranger P, Brox Jl, et al. Costs of shoulder pain and resource use in primary health care: a cost-of-illness study in Sweden. BMC Musculoskelet Disord 2012;13:17.

18 Anema JR, van der Beek AJ. Medically certified sickness absence. BMJ 2008;337:a1174.

19 Schram JLD, Schuring M, Oude Hengel KM, et al. Health-Related educational inequalities in paid employment across 26 European countries in 2005-2014: repeated cross-sectional study. BMJ Open 2019;9:e024823.

20 Viikari-Juntura E, Leinonen T, Virta LJ, et al. Early part-time sick leave results in considerable savings in social security costs at national level: an analysis based on a quasi-experiment in Finland. Scand $J$ Work Environ Health 2019;45:203-8.

21 Melkevik O, Clausen T, Pedersen J, et al. Comorbid symptoms of depression and musculoskeletal pain and risk of long term sickness absence. BMC Public Health 2018;18:981.

22 Dalbøge A, Frost P, Andersen JH, et al. Surgery for subacromial impingement syndrome in relation to intensities of occupational mechanical exposures across 10-year exposure time windows. Occup Environ Med 2018;75:176-82.

23 Moen VP, Drageset J, Eide GE, et al. Dimensions and predictors of disability-A baseline study of patients entering somatic rehabilitation in secondary care. PLoS One 2018;13:e0193761.

$24 \mathrm{Kwak}$ J, Kim HK, Kim T, et al. The prevalence and characteristics of depression in work-related musculoskeletal disease. Ann Rehabil Med 2012;36:836-40.

25 von Knoch M, Enders D, Schlothauer NI, et al. Duration of sick leave after shoulder arthroscopy in Germany: analysis of health care data. Arch Orthop Trauma Surg 2016;136:843-8.

26 Dorner TE, Alexanderson K, Svedberg P, et al. Sickness absence due to back pain or depressive episode and the risk of all-cause and diagnosis-specific disability pension: a Swedish cohort study of 4,823,069 individuals. Eur J Pain 2015;19:1308-20.

27 Diercks R, Bron C, Dorrestijn O, et al. Guideline for diagnosis and treatment of subacromial pain syndrome: a multidisciplinary review by the Dutch orthopaedic association. Acta Orthop 2014;85:314-22.

28 Koljonen P, Chong C, Yip D. Difference in outcome of shoulder surgery between workers' compensation and nonworkers' compensation populations. Int Orthop 2009;33:315-20.
29 Faber E, Kuiper JI, Burdorf A, et al. Treatment of impingement syndrome: a systematic review of the effects on functional limitations and return to work. J Occup Rehabil 2006;16:6-24.

30 Englund M, Guermazi A, Gale D, et al. Incidental meniscal findings on knee MRI in middle-aged and elderly persons. $N$ Engl $J$ Med 2008;359:1108-15.

31 Schwartzberg R, Reuss BL, Burkhart BG, et al. High prevalence of superior Labral tears diagnosed by MRI in middle-aged patients with asymptomatic shoulders. Orthop J Sports Med 2016;4:232596711562321.

32 Denard PJ, Lädermann A, Burkhart SS. Long-Term outcome after arthroscopic repair of type II slap lesions: results according to age and workers' compensation status. Arthroscopy 2012;28:451-7.

33 Verma NN, Garretson R, Romeo AA. Outcome of Arthroscopic Repair of Type II SLAP Lesions in Worker's Compensation Patients. HSS $\mathrm{Jrnl}$ 2007;3:58-62.

34 Skare O, Schrøder CP, Reikerås O, et al. Efficacy of labral repair, biceps tenodesis, and diagnostic arthroscopy for slap lesions of the shoulder: a randomised controlled trial. BMC Musculoskelet Disord 2010;11:228.

35 Brox JI, Schrøder CP, Skare Ø, et al. Author response-sham surgery versus labral repair or biceps tenodesis for type II slap lesions of the shoulder: a three-armed randomised clinical trial. Br J Sports Med 2017;51:1778-9.

36 Grøvle L, Haugen AJ, Keller A, et al. Poor agreement found between self-report and a public registry on duration of sickness absence. $J$ Clin Epidemiol 2012;65:212-8.

37 Reme SE, Eriksen HR. Is one question enough to screen for depression? Scand J Public Health 2010;38:618-24.

38 Omair A, Lie BA, Reikerås O, et al. Genetic contribution of catecholO-methyltransferase variants in treatment outcome of low back pain: a prospective genetic association study. BMC Musculoskelet Disord 2012;13:76.

39 King M, Essick C, Bearman P, et al. Medical school gift restriction policies and physician prescribing of newly marketed psychotropic medications: difference-in-differences analysis. BMJ 2013;346:f264.

40 Friedman J, Hastie T, Tibshirani R. Regularization paths for generalized linear models via coordinate descent. J Stat Softw 2010;33:1-22.

41 A language and envronment for statistical computing program. $R$ package version 3.6.1. Vienna, Austria: R Foundation for Statistical Computing, 2019.

42 Paoli AR, Gold HT, Mahure SA, et al. Treatment for symptomatic slap tears in middle-aged patients comparing repair, biceps Tenodesis, and Nonoperative approaches: a cost-effectiveness analysis. Arthroscopy: The Journal of Arthroscopic \& Related Surgery 2018;34:2019-29.

43 OECD. Public spending on incapacity (indicator), 2019.

44 Statistics O. See health status and labour force statistics, 2019. Available: https://www.stats.oecd.org

45 Adobor RD, Joranger P, Steen $\mathrm{H}$, et al. A health economic evaluation of screening and treatment in patients with adolescent idiopathic scoliosis. Scoliosis 2014;9:21.

46 Reme SE, Monstad K. Fyhn T, et al. A randomized controlled multicenter trial of individual placement and support for patients with moderate-to-severe mental illness. Scand J Work Environ Health 2019;45:33-41.

47 Trivedi D. Cochrane review summary: interventions to improve return to work in depressed people. Prim Health Care Res Dev 2018;19:107-9.

48 Brox JI, Lange JE, Steen H. Comorbidity influenced health-related quality of life of 390 patients with idiopathic scoliosis at long-term follow-up. Eur J Phys Rehabil Med 2014;50:73-81.

49 Provencher MT, McCormick F, Dewing C, et al. A prospective analysis of 179 type 2 superior labrum anterior and posterior repairs: outcomes and factors associated with success and failure. Am J Sports Med 2013;41:880-6. 